\title{
Luminescent protection against radiation damage in wide-gap materials
}

\author{
A. Lushchik*, Ch. Lushchik, P. Liblik, A. Maaroos, V.N. Makhov, F. Savikhin, E. Vasil'chenko \\ Institute of Physics, University of Tartu, Riia 142, 51014 Tartu, Estonia
}

\section{A R T I C L E I N F O}

Available online 7 May 2009

\section{Keywords:}

Luminescence and hot electrons

Radiation defects

$\mathrm{Al}_{2} \mathrm{O}_{3}: \mathrm{Sc}^{3+}, \mathrm{Gd}^{3+}$

\begin{abstract}
A B S T R A C T
In the wide-gap metal oxides, with $E_{\mathrm{g}}$ lower than the formation energy of a pair of Frenkel defects, hot recombination of nonrelaxed electrons and holes cause the creation of defects under the conditions of high-density excitation. Novel manifestations of the fast direct energy transfer by hot electrons to impurity centers (e.g., in $\mathrm{Al}_{2} \mathrm{O}_{3}: \mathrm{Sc}^{3+}$ and $\mathrm{Al}_{2} \mathrm{O}_{3}: \mathrm{Gd}^{3+}$ ) or to intrinsic defects $\left(\mathrm{F}\right.$ and $\mathrm{F}^{+}$centers induced by the previous irradiation of $\mathrm{Al}_{2} \mathrm{O}_{3}$ with swift heavy ions) have been revealed using the methods of low-temperature cathodo- and photoluminescence. The contribution of the solid-state analogue of the Franck-Hertz effect as well as of the multiplication processes of electronic excitations to the suppression of hot recombination and the increase of radiation resistance of dielectrics has been analysed.
\end{abstract}

(c) 2009 Elsevier B.V. All rights reserved.

\section{Introduction}

A controlled thermonuclear fusion is one of the most important problems of modern physics and energetics [1]. The success can be achieved by solving many related tasks. Among them, there is a seldom mentioned but a very urgent taska significant increase of radiation resistance of construction and diagnostics materials for future industrial fusion reactors.

In the present study, attention will be focused on the prospects of reducing the radiation damage, primarily the creation of Frenkel defects (FDs) and their nanosize associations in inorganic wide-gap materials (WGMs). The analysis is based on our recent experimental results on luminescence and radiation physics in WGMs, while the historical aspect of the problem is considered, for instance, in Refs. [2,3]. It has long been established that two groups of mechanisms are responsible for the creation of FDs in WGMs, where the creation energy of a pair of FDs $\left(E_{\mathrm{FD}}\right)$ is lower than the energy gap $\left(E_{\mathrm{g}}\right)$. Besides knock-out (impact) mechanisms, FDs are efficiently created via the nonimpact mechanisms as well: at the decay of self-trapping excitons or at the recombination of cold (totally relaxed) conduction electrons (e) with valence holes (h). Even in highly resistant WGMs with $E_{\mathrm{FD}}>E_{\mathrm{g}}\left(\mathrm{MgO}, \mathrm{Al}_{2} \mathrm{O}_{3}\right.$, $\mathrm{MgAl}_{2} \mathrm{O}_{4}, \mathrm{Y}_{3} \mathrm{Al}_{5} \mathrm{O}_{12}$, etc.) the nonimpact mechanisms of radiation damage should be taken into account. The energy released at the recombination of hot (nonrelaxed) carriers or the decay of cation excitations can be sufficient for the creation of FDs in these WGMs. It was shown recently that the efficiency of FD creation via hot recombination of carriers is high under the conditions of high

\footnotetext{
* Corresponding author. Fax: +3727383033.

E-mail address: aleksandr.lushchik@ut.ee (A. Lushchik).
}

density of electronic excitations (EEs) formed during irradiation [4-6]. Such conditions are realized under the irradiation of WGMs with swift heavy ions. It is worth noting that about $99.9 \%$ of the energy of $\sim 2 \mathrm{GeV}$ gold or uranium ion is spent on the electronic energy losses (see, e.g., Ref. [7]), while the ratio of the mean nuclear energy loss (elastic collisions) to the electronic energy loss (formation of EEs) is close to unity for 3-10 MeV Au ions [8].

The main goal of the present study is to consider the use of the solid-state analogue of the Franck-Hertz effect (FHE) in gases for the weakening of hot $\mathrm{e}-\mathrm{h}$ recombination causing the creation of FDs in WGMS with $E_{\mathrm{FD}}>E_{\mathrm{g}}$. In WGMs, the FHE manifests itself as the fast direct transfer of the energy excess (with respect to the minimum energy within the band) of a hot conduction electron/ valence hole to an impurity/defect. The energy of the excited state of the impurity/defect is transformed into a luminescence quantum or into heat (phonon package). The solid-state analogue of $\mathrm{FHE}$ was revealed in $\mathrm{ZnS}: \mathrm{Mn}^{2+}[9], \mathrm{KCl}: \mathrm{Tl}^{+}, \mathrm{RbCl}^{2} \mathrm{Tl}^{+}$and $\mathrm{RbCl}: \mathrm{Ag}^{+}[10,11], \mathrm{BaMgAl}_{10} \mathrm{O}_{17}: \mathrm{Eu}^{2+}$ [12], $\mathrm{LaF}_{3}: \mathrm{RE}^{3+}$ [13], $\mathrm{MgO}: \mathrm{Cr}^{3+}$ [4] and $\mathrm{Al}_{2} \mathrm{O}_{3}: \mathrm{Cr}^{3+}$ [5]. Particular emphasis has been laid on the "self-protection" of WGMs against the creation of FDs due to the solid-state analogue of FHE with the participation of luminescent defects induced in the course of irradiation.

\section{Experimental}

$\alpha-\mathrm{Al}_{2} \mathrm{O}_{3}: \mathrm{Sc}^{3+}$ were grown by the Czochralski technique, undoped $\alpha-\mathrm{Al}_{2} \mathrm{O}_{3}$ single crystals by the horizontal-oriented crystallization. Powder samples of $\alpha-\mathrm{Al}_{2} \mathrm{O}_{3}: \mathrm{Gd}^{3+}$ were synthesized by the method of solid-state reactions with the final firing at $1300{ }^{\circ} \mathrm{C}$. The starting materials for synthesis were $\gamma-\mathrm{Al}_{2} \mathrm{O}_{3}$ (99.997\%) and $\mathrm{Gd}_{2} \mathrm{O}_{3}$ (99.995\%). Irradiation by uranium swift ions 
( $\sim 2.5 \mathrm{GeV}$, fluence of $\left.3 \times 10^{10}-3 \times 10^{12} \mathrm{ions} / \mathrm{cm}^{2}\right)$ was performed at the UNILAC linear accelerator (GSI, Darmstadt) at room temperature.

The cathodoluminescence (CL) spectra were measured using a two-channel system in the regions of $1.8-6.0$ and $4-11 \mathrm{eV}$ at the excitation by an electron beam (typically $5 \mathrm{keV}, 300 \mathrm{nA}, 2 \mathrm{~mm}^{-2}$ spot) at $6 \mathrm{~K}$. After the electron irradiation was stopped, it was possible to register the spectra of phosphorescence at $6 \mathrm{~K}$ and the curves of thermostimulated luminescence (TSL, for an integral signal or a certain emission selected through a double monochromator) of the irradiated sample with a constant heating rate of $\beta=10 \mathrm{~K} \mathrm{~min}^{-1}$. The experiments with synchrotron radiation were carried out at the SUPERLUMI station of HASYLAB at DESY, Hamburg.

\section{Experimental results and discussion}

The energy-band structure of $\mathrm{MgO}$ and $\alpha-\mathrm{Al}_{2} \mathrm{O}_{3}$ was studied by means of photoelectric (see, e.g., Ref. [2]) and highly sensitive luminescence methods (see, e.g., Ref. [4]). $\mathrm{MgO}$ and $\alpha-\mathrm{Al}_{2} \mathrm{O}_{3}$ single crystals have wide energy gaps (at $6 \mathrm{~K}, E_{\mathrm{g}}$ equals 7.8 and $9.4 \mathrm{eV}$, respectively) and relatively wide $(\sim 7-8 \mathrm{eV})$ and continuous (without energetic gaps) valence bands. Notice that the fast relaxation of valence holes in $\mathrm{SiO}_{2}$ is hampered because of the energy gap of $\sim 1.5 \mathrm{eV}$ inside the valence band [4].

Fig. 1 shows a simplified energy-band diagram for WGMs of $\mathrm{MgO}-$ and $\mathrm{Al}_{2} \mathrm{O}_{3}$-type. Figure demonstrates four main mechanisms of the multiplication of EEs, when an exciting photon causes the creation of two e-h pairs, an e-h and a secondary anion exciton, an e-h pair and an excited state of an impurity/defect $\left(E_{\mathrm{id}}^{*}\right)$. The latter case is connected with the transfer of the energy excess of a hot carrier (e or h) from a primary e-h pair to an impurity/defect and can be considered as the solid-state analogue of FHE in gases. By now, the case $(d)$ is experimentally revealed in $\mathrm{BaMgAl}_{10} \mathrm{O}_{17}: \mathrm{Eu}^{2+}[12]$. The separation of the FHE on impurity centers is rather difficult even under the most favourable conditions when a hot conduction electron causes a spin-forbidden transition (exchange between a conduction electron and an electron from an impurity center) in an impurity center. In $\mathrm{KCl}: \mathrm{Tl}$, the excitation function for such transitions in $\mathrm{Tl}^{+}$(similar to ${ }^{1} \mathrm{~S}_{0} \rightarrow{ }^{3} \mathrm{P}_{1}$ in mercury atoms) has a resonant behaviour [10]. In the case of ${ }^{1} \mathrm{~S}_{0} \rightarrow{ }^{1} \mathrm{P}_{1}$-type spin-allowed transitions, the excitation function of center emission smoothly increases above the threshold value with the rise of the energy of

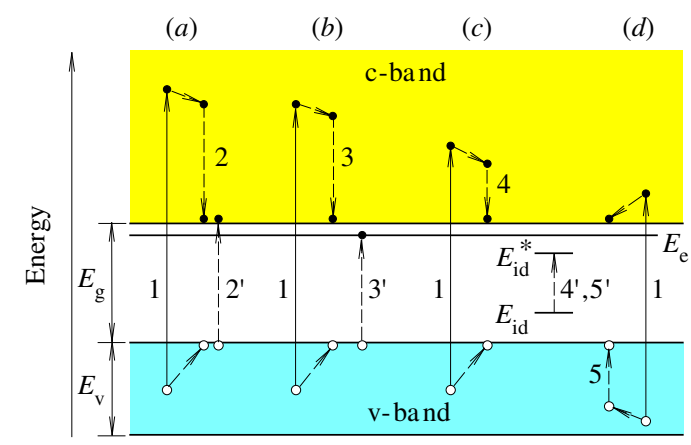

Fig. 1. A simplified energy-band diagram for WGMs of $\mathrm{MgO}$ - and $\mathrm{Al}_{2} \mathrm{O}_{3}$-type. The multiplication processes connected with the creation of a secondary e-h pair (case a) or a secondary anion exciton (case b) by a hot conduction electron as well as the excitation of an impurity/defect center by a hot electron (case c) or a hot valence hole (case d) due to nonradiative Auger transitions $\left(2 \rightarrow 2^{\prime}, 3 \rightarrow 3^{\prime}, 4 \rightarrow 4^{\prime}, 5 \rightarrow 5^{\prime}\right)$. All processes start with the absorption of an exciting photon (showed by arrow line 1 ). The inclined dashed arrow lines demonstrate nonradiative transition at carrier relaxation inside energy bands. electrons by several electron-volts, thus, impeding the separation of the solid-state analogue of FHE among other mechanisms of EE multiplication.

It should be pointed out that there are two types of impurity centers (the cases of direct and indirect activation): (i) the lowest excited state of an impurity center is an excitation of an impurity ion or (ii) the lowest excited state of the center is connected with ligands surrounding an impurity ion. The first type of the impurity center is typical of alkali halide crystals doped with mercury-like $s^{2}$ ions, but near-impurity excitation should be taken into consideration as well. $\mathrm{Na}^{+}$in $\mathrm{KCl}$ is a representative of the second type of centers. Among metal oxides, $\mathrm{Al}_{2} \mathrm{O}_{3}: \mathrm{Cr}^{3+}[5]$ and $\mathrm{MgO}: \mathrm{Ge}^{2+}[14]$ are assigned to the first type (again near-impurity EEs should be considered) and $\mathrm{Sc}^{3+}$ in $\mathrm{Al}_{2} \mathrm{O}_{3}$ [15] or $\mathrm{Be}^{2+}$ in $\mathrm{MgO}$ [16] to the second type of impurity centers.

The study of $\mathrm{CL}$ in $\mathrm{Al}_{2} \mathrm{O}_{3}: \mathrm{Sc}^{3+}$ has been continued (see Ref. [15]). The CL spectrum contains two broad bands with the maxima at $7.6 \mathrm{eV}$ (luminescence of self-trapped excitons) and $5.6 \mathrm{eV}$. The latter luminescence is related to the excitations of oxygen ions located near $\mathrm{Sc}^{3+}$ (the so-called near-impurity localized EEs). The intensity of $\mathrm{Sc}^{3+}$ emission drastically decreases by four orders of magnitude in $\sim 1 \mathrm{~s}$ after an electron irradiation is stopped. A similar drop of luminescence intensity occurs at the excitation of $\alpha-\mathrm{Al}_{2} \mathrm{O}_{3}: \mathrm{Sc}^{3+}$ by $25-33 \mathrm{eV}$ photons at $8 \mathrm{~K}$.

Fig. 2 presents a simplified energy-band diagram for $\mathrm{Al}_{2} \mathrm{O}_{3}$ and the excitation spectrum of $5.6 \mathrm{eV}$ emission of $\mathrm{Sc}^{3+}$ centers measured in the region of $7-37 \mathrm{eV}$ for $\mathrm{Al}_{2} \mathrm{O}_{3}: \mathrm{Sc}^{3+}(600 \mathrm{ppm})$ at $8 \mathrm{~K}$. The emission efficiency is $\mathrm{QY} \cong 0.7$ at the direct excitation of the oxygen ions surrounding $\mathrm{Sc}^{3+}(h v \approx 8.5 \mathrm{eV})$. Each photon of $10 \mathrm{eV}$ is able to form only one $\mathrm{e}-\mathrm{h}$ pair. In the region of fundamental absorption at $18-23 \mathrm{eV}$, the values of absorption constant are high resulting in an efficient near-surface nonradiative recombination and the lowering of QY. A sharp rise of $\mathrm{QY}$ for $\mathrm{Sc}^{3+}$ emission takes place at higher values of $h v$, and in the region of $30 \mathrm{eV}$ the value of $\mathrm{QY}$ exceeds the one typical of the direct excitation of scandium centers $(h v=8.5 \mathrm{eV})$. Exciting photons of $25-37 \mathrm{eV}$ cause the multiplication processes and, consequently, a high local density of EEs. An exciting photon of $30-33 \mathrm{eV}$ is able to form up to three e-h pairs: a photon causes the ionization of the $2 \mathrm{~s}^{2}$ shell of an oxygen ion and the formation of a $3 p$ conduction electron; the third $\mathrm{e}-\mathrm{h}$ pair is formed due to the

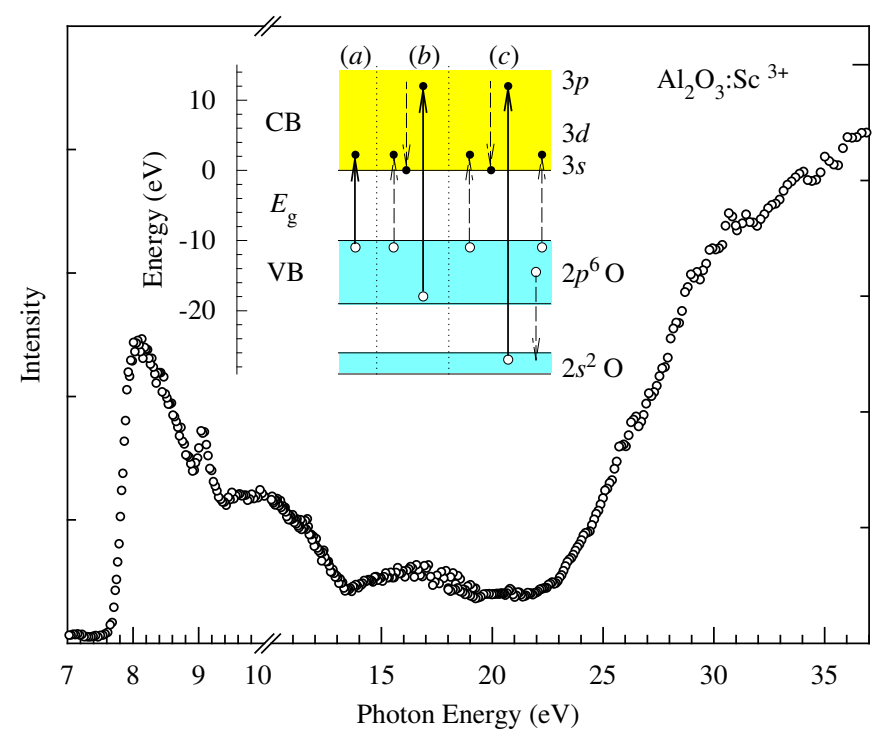

Fig. 2. The excitation spectrum of $5.6 \mathrm{eV}$ emission of $\mathrm{Sc}^{3+}$ centers measured using synchrotron radiation for $\alpha-\mathrm{Al}_{2} \mathrm{O}_{3}: \mathrm{Sc}^{3+}(600 \mathrm{ppm})$ at $8 \mathrm{~K}$. Inset shows a simplified energy-band diagram of an $\alpha-\mathrm{Al}_{2} \mathrm{O}_{3}$ crystal. 
Auger recombination between $2 \mathrm{p}$ electron and $2 \mathrm{~s}$ hole (see case (c) in Fig. 2 and Ref. [15] for details). So, there is a similarity between the behaviour of $\mathrm{CL}$ and the luminescence under photoexcitation in the multiplication regime at the instant the excitation is switched off. On the other hand, the difference in intensities between a steady photoluminescence (when an exciting photon of $10 \mathrm{eV}$ forms only one $\mathrm{e}-\mathrm{h}$ pair) and phosphorescence is not so large.

In addition to the impurity centers of both types, intrinsic structural defects created in the course of irradiation can also serve as efficient transformers of the energy absorbed by WGMs at the irradiation. Our recent experiments with $\mathrm{LiF}, \mathrm{MgO}$ and $\mathrm{Al}_{2} \mathrm{O}_{3}$ single crystals previously irradiated with ${ }^{198} \mathrm{Au}$ or ${ }^{238} \mathrm{U}$ swift ions $\left(\sim 2.5 \mathrm{Gev}\right.$, fluence of $3 \times 10^{10}-3 \times 10^{12}$ ions $\left./ \mathrm{cm}^{2}\right)$ [8,16] and fast neutrons $\left(\sim 2-3 \mathrm{MeV}, 10^{16}-10^{17} \mathrm{n} / \mathrm{cm}^{2}\right)[5,16]$ support the validity of this statement. The bleaching action of an exciting light or $\mathrm{X}$-rays on phosphors has long been known. The destructive role of mobile excitons and recombining e-h pairs with respect to the efficiency of defect creation is even more pronounced at the irradiation of WGMs with high-energy particles. According to experimental data and theoretical estimates [17], the creation of defects in combination with their partial destruction in the course of irradiation causes the spatial separation of the aggregates of vacancies and the aggregates of interstitials.

According to the recent experiments, the statement on the dominant role of impact mechanisms of FD creation in pure and stoichiometric $\alpha-\mathrm{Al}_{2} \mathrm{O}_{3}$ with $E_{\mathrm{FD}}>E_{\mathrm{g}}$ should be more exactly defined. In the tracks of $\sim 2.5 \mathrm{GeV}$ Au or $\mathrm{U}$ ion (energy losses of $\geqslant 20 \mathrm{keV} / \mathrm{nm}$, ion range of several tens of $\mu \mathrm{m}$ ) with an extremely high density of EEs, elastic collisions contribute to defect creation mainly at the end of the ion range, while just nonimpact mechanisms connected with ionisation losses (formation of EEs) are responsible for the radiation damage along the main part of the ion track. This theoretical estimation has been confirmed by the experiments on the topography of the induced optical absorption of $\mathrm{F}$ and $\mathrm{F}^{+}$centers (one or two electrons localized in a vacancy) along the ion tracks (see, e.g. Ref. [7]) and the sounding by an electron beam [6,16]. Fig. 3 shows the CL spectra simultaneously measured at $6 \mathrm{~K}$ in two different spectral regions (2.5-4.5 and 6.5-8.5eV) for a highly pure and stoichiometric $\alpha-\mathrm{Al}_{2} \mathrm{O}_{3}$ single crystal, previously irradiated with ${ }^{238} \mathrm{U}$ ions at $295 \mathrm{~K}$. Five-keV electrons with the penetration depth of $\sim 3 \mu \mathrm{m}$ can excite $\mathrm{F}$ and $\mathrm{F}^{+}$centers which were formed far away from the end of the ion track. For $\mathrm{Al}_{2} \mathrm{O}_{3}$ irradiated in the regime of single ion tracks (fluence of $\sim 3 \times 10^{10}$ ions $/ \mathrm{cm}^{2}$ ), the CL contains the emission of $\mathrm{F}(3 \mathrm{eV})$ and $\mathrm{F}^{+}$centers $(3.8 \mathrm{eV})$ as well as a broadened luminescence band $(\sim 7.5 \mathrm{eV})$ of self-trapped excitons (formed at

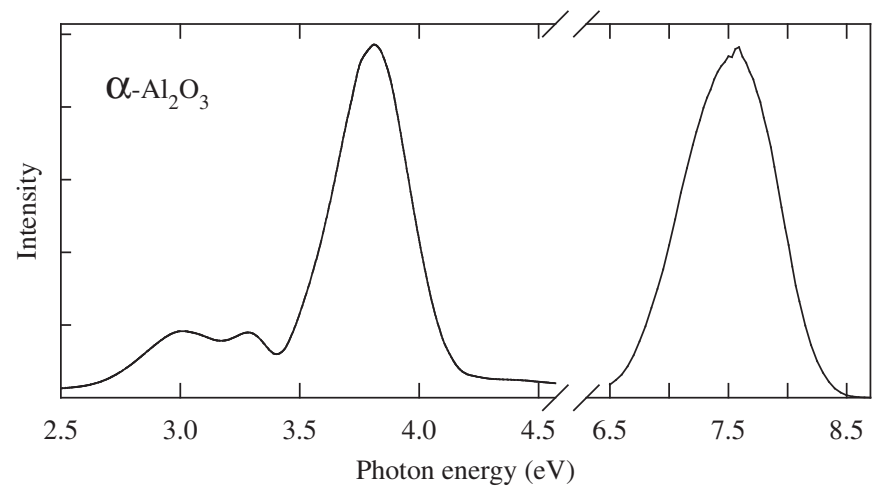

Fig. 3. The cathodoluminescence spectrum measured at the excitation of $\alpha-\mathrm{Al}_{2} \mathrm{O}_{3}$ previously irradiated with ${ }^{238} \mathrm{U}$ ions $\left(2.5 \mathrm{GeV}, \sim 3 \times 10^{10} \mathrm{ions} / \mathrm{cm}^{2}, 295 \mathrm{~K}\right)$ by $5 \mathrm{keV}$ electrons at $6 \mathrm{~K}$. e-h recombination) from slightly disturbed crystal regions between the tracks. In 1-2 s, after the electron irradiation was stopped the intensity of these emission bands drastically decreased by four orders of magnitude.

Unfortunately, the luminescence of many interstitial associations cannot be excited in $\mathrm{Al}_{2} \mathrm{O}_{3}$ and $\mathrm{MgO}$. However, these intrinsic defects can rapidly transform a part of the energy absorbed at the irradiation into heat, thus, reducing the probability of hot e-h recombination and the creation of new radiation defects. In such a manner, the crystal provides a "selfprotection" against radiation damage even without its doping with luminescent impurities (i.e. luminescent protection).

At present, there is a strong interest in gadolinium-containing phosphors. Gd nuclei have a large effective cross-section for the interaction with thermal neutrons. In addition, Gd nuclei can be excited by fast neutrons (e.g., $14 \mathrm{MeV}$ fusion neutrons) via enormously inertial $n, \alpha$-reactions. It is obvious that the materials intended to be used as dosimetric ones should possess a high radiation resistance. From this viewpoint, $\mathrm{CaSO}_{4}: \mathrm{Gd}^{3+}, \mathrm{Dy}^{3+}$ phosphors (see Ref. [18]) are unacceptable because of the instability of $\mathrm{SO}_{4}^{2-}$ oxyanions. Taking into account a high radiation resistance of $\mathrm{Al}_{2} \mathrm{O}_{3}: \mathrm{Ce}^{3+}$ cathodophosphors $\left(E_{\mathrm{FD}}>E_{\mathrm{g}}\right)$ and highly efficient processes of the multiplication of EEs in $\mathrm{Al}_{2} \mathrm{O}_{3}$ [15], $\mathrm{Al}_{2} \mathrm{O}_{3}: \mathrm{Gd}^{3+}$ and $\mathrm{MgO}: \mathrm{Gd}^{3+}$ phosphors have been synthesized and investigated. Fig. 4 shows the $\mathrm{CL}$ spectrum measured for an $\mathrm{Al}_{2} \mathrm{O}_{3}: \mathrm{Gd}^{3+}$ phosphor in a wide spectral region at $6 \mathrm{~K}$. The $4 \mathrm{f}^{7} \rightarrow 4 \mathrm{f}^{7}$ radiative transitions in $\mathrm{Gd}^{3+}$ are registered at 3.9 and $5.95 \mathrm{eV}$ and in a red spectral region. In our opinion, an $\mathrm{Al}_{2} \mathrm{O}_{3}: \mathrm{Gd}^{3+}$ phosphor after its additional doping with high-temperature luminescence centers (e.g., $\mathrm{Dy}^{3+}$ ions) can be considered as a promising material for thermoluminescence dosimetry of fusion neutrons.

In conclusion, three channels of the transformation of the energy absorbed at irradiation are realized in wide-gap oxides with $E_{\mathrm{FD}}>E_{\mathrm{g}}$ : creation of FDs, heat and luminescence. The probability redistribution between these channels with the suppression of nonimpact mechanisms of defect creation can be performed by doping of WGMs with some luminescent (or nonluminescent) impurity centers/intrinsic defects, which can be excited by hot electrons/holes. The solid-state analogues of the Franck-Hertz effect as well as a high local density of

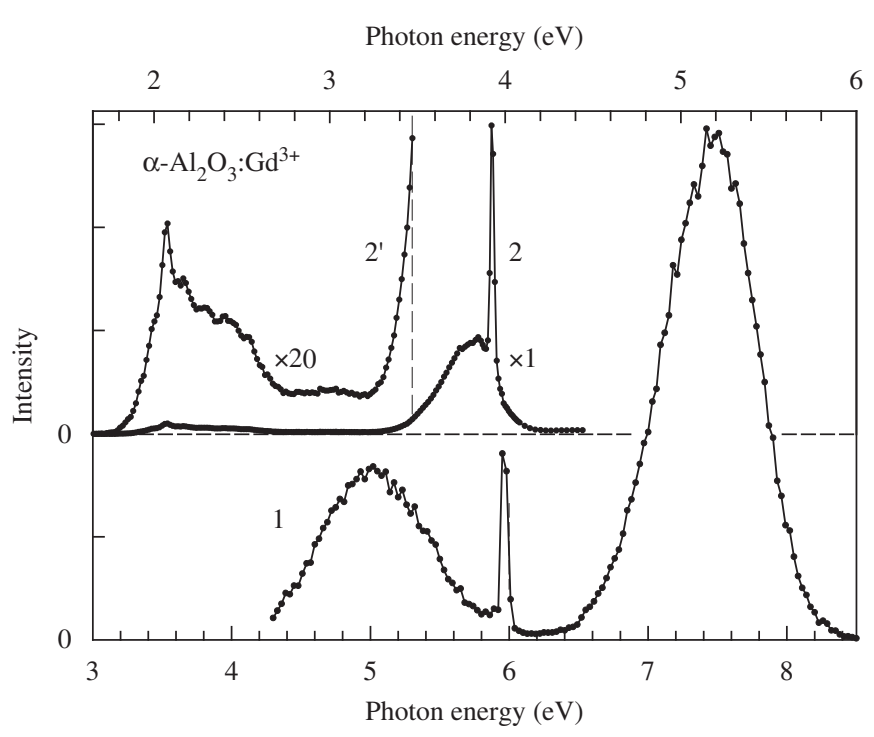

Fig. 4. The cathodoluminescence spectra (excitation by $8 \mathrm{keV}$ electrons) simultaneously measured in two spectral regions $(2.5-4.5$ and $6.5-8.5 \mathrm{eV}$ ) for $\alpha$ $\mathrm{Al}_{2} \mathrm{O}: \mathrm{Gd}^{3+}(0.2 \mathrm{~mol} \%)$ at $6 \mathrm{~K}$. 
excitations caused due to the formation of secondary EE by hot conduction electrons increase the efficiency of luminescence processes and heat release, while the efficiency of radiation damage will be decreased.

\section{Acknowledgements}

We are grateful to Prof. Kurt Schwartz for ion-irradiations and valuable discussions. This work was partly supported by the Estonian Science Foundation (Grant 6652) and the European Community Research Infrastructure Action within the FP6 Program through the Contract RII3-CT-2004-506008 (IA-SFS).

\section{References}

[1] V.L. Ginzburg, Phys. Uspekhi 47 (2004) 1155.

[2] N. Itoh, A.M. Stoneham, Material Modification by Electronic Excitation, University Press, Cambridge, 2000.

[3] Ch.B. Lushchik, A.Ch. Lushchik, Decay of Excitonic Excitations with Defect Formation in Solids, Nauka, Moscow, 1989.

[4] A. Lushchik, Ch. Lushchik, M. Kirm, V. Nagirnyi, F. Savikhin, E. Vasil'chenko, Nucl. Instrum. Methods B 250 (2006) 330.

[5] V.N. Makhov, A. Lushchik, Ch.B. Lushchik, M. Kirm, E. Vasil'chenko, S. Vielhauer V.V. Harutunyan, E. Aleksanyan, Nucl. Instrum. Methods B 266 (2008) 2949
[6] A. Lushchik, T. Kärner, Ch. Lushchik, E. Vasil'chenko, S. Dolgov, V. Issahhanyan, P. Liblik, Phys. Status Solidi C 4 (2007) 1084.

[7] K. Schwartz, C. Trautmann, A.S. El-Said, R. Neumann, M. Toulemonde, W. Knolle, Phys. Rev. B 70 (2004) 184104.

[8] A. Lushchik, Ch. Lushchik, K. Schwartz, E. Vasil'chenko, R. Papaleo, V. Sorokin, A.E. Volkov, R. Neumann, C. Trautmann, Phys. Rev. B 76 (2007) 054114.

[9] Ch.B. Lushchik, E.R. Ilmas, T.I. Savikhina, in: Proceedings of the International Conference on Luminescence, Budapest, 1966, p. 99.

[10] E. Feldbach, M. Kamada, M. Kirm, A. Lushchik, Ch. Lushchik, I. Martinson, Phys. Rev. B 56 (1997) 13908.

[11] A. Lushchik, M. Kamada, M. Kirm, Ch. Lushchik, I. Martinson, Radiat. Meas. 29 (1998) 229.

[12] A. Lushchik, Ch. Lushchik, E. Feldbach, I. Kudrjavtseva, P. Liblik, A. Maaroos, V. Nagirnyi, E. Vasil'chenko, F. Savikhin, Proc. SPIE 5946 (2005) 594609.

[13] Yu.M. Aleksandrov, V.N. Makhov, M.N. Yakimenko, Sov. Phys.—Solid State 29 (1987) 1092.

[14] S.A. Dolgov, M. Kirm, T. Kärner, A. Lushchik, A. Maaroos, Phys. Scr. 59 (1999) 481.

[15] M. Kirm, G. Zimmerer, E. Feldbach, A. Lushchik, Ch. Lushchik, F. Savikhin, Phys. Rev. B 60 (1999) 502.

[16] A. Lushchik, Ch. Lushchik, K. Schwartz, E. Vasil'chenko, T. Kärner, I. Kudryavtseva, V. Isakhanyan, A. Shugai, Nucl. Instrum. Methods B 266 (2008) 2868.

[17] E.A. Kotomin, V.V. Kuzovkov, Rep. Prog. Phys. 55 (1992) 2079.

[18] I. Kudryavtseva, P. Liblik, A. Lushchik, A. Maaroos, E. Vasil'chenko Z. Azmaganbetova, T. Nurakhmetov, B. Toxanbayev, J. Lumin, this issue, doi:10.1016/j.jlumin.2009.04.082. 